\title{
The Impact of Additional Radiosonde Observations on the Analysis of Disturbances in the South China Sea during VPREX2010
}

\author{
Miki Hattori ${ }^{1}$, Jun Matsumoto ${ }^{1,2}$, Shin-Ya Ogino ${ }^{1}$, Takeshi Enomoto ${ }^{1,3}$, and Takemasa Miyoshi ${ }^{1,4,5}$ \\ ${ }^{1}$ Japan Agency for Marine-Earth Science and Technology (JAMSTEC), Yokosuka, Japan \\ ${ }^{2}$ Tokyo Metropolitan University, Hachioji, Japan \\ ${ }^{3}$ Disaster Prevention Research Institute, Kyoto University, Uji, Japan \\ ${ }^{4}$ RIKEN Advanced Institute for Computational Science, Kobe, Japan \\ ${ }^{5}$ University of Maryland, College Park, Maryland, The United States of America
}

\begin{abstract}
The impact of additional radiosonde observations during the Vietnam-Philippines Rainfall Experiment 2010 (VPREX2010) was investigated by performing observing system experiments using the local ensemble transform Kalman filter (LETKF) and the atmospheric general circulation model for the Earth Simulator (AFES). During the experimental period from 15 September to 15 October, 2010, a westward-propagating disturbance was developed in the South China Sea and caused heavy rainfall on the east coast of Vietnam and Hainan Island. By assimilating the additional radiosondes, significant increases in wind speed, temperature and specific humidity were detected in the lower troposphere around the disturbance. In addition, the analysis ensemble spread for meridional wind decreased by $5-25 \%$ across the Indochina Peninsula, Philippines Sea and western Pacific to the south of Japan. Moreover, winds became stronger around the disturbance due to the additional observations, and the ensemble spread for wind speed became larger. The results show that the disturbance in an early stage of development was not well detected in the South China Sea without the use of additional radiosonde observations. Therefore, it is suggested that continuous and intensive radiosonde observations in Vietnam and the Philippines are essential for the improvement of the objective analysis of such disturbances.

(Citation: Hattori, M., J. Matsumoto, S. Ogino, T. Enomoto, and T. Miyoshi, 2016: The impact of additional radiosonde observations on the analysis of disturbances in the South China Sea during VPREX2010. SOLA, 12, 75-79, doi:10.2151/sola.2016018.)
\end{abstract}

\section{Introduction}

The central Vietnam coastal region experiences an annual rainy season from October to November (Yokoi et al. 2007). Yokoi and Matsumoto (2008) suggest that the cold surge from northern China and southerly wind anomalies over the central South China Sea, which are associated with tropical depression-type disturbances, are important for the occurrence of heavy rainfall in central Vietnam. However, observations around the South China Sea are insufficient to detect such key phenomena, inducing heavy rainfall.

The Vietnam-Philippines Rainfall Experiment 2010 (VPREX 2010) observation campaign was conducted by the Japan Agency for Marine-Earth Science and Technology (JAMSTEC), National Hydrometeorological Service of Vietnam (NHMS) and Philippine Atmospheric, Geophysical and Astronomical Service Administration (PAGASA) in September 2010 through January 2011 to address these observational challenges. VPREX2010 was focused on westward-propagating disturbances that affected the coastal region of Vietnam. Additional radiosonde observations were conducted in Vietnam and the Philippines to observe synoptic

Corresponding author: Miki Hattori, JAMSTEC, 2-15 Natsushima-cho, Yokosuka 237-0061, Japan. E-mail: mhattori@jamstec.go.jp. (C2016, the Meteorological Society of Japan. conditions related to the generation and development of westwardpropagating disturbances.

Although these additional observations were transmitted to operational centers to be assimilated in their objective analysis, local operational weather services require the knowledge on more effective observations (positions, variables, temporal and spatial intervals, etc.) from a cost-effectiveness perspective. An effective observational design is strongly required in tropical and subtropical regions because fewer observation points and lower observation frequency are available compared to the mid-latitudes.

The present study evaluates the impact of the additional radiosonde observations using an ensemble reanalysis of ALERA2 (AFES-LETKF experimental ensemble reanalysis 2, Enomoto et al. 2013) as a reference. The purpose of this study is to assess the influence of the additional radiosonde observations on the analysis field of ALERA2 associated with the westward-propagating disturbances that develop in the South China Sea and cause heavy rainfall in central Vietnam.

\section{Description of VPREX2010 and OSE}

Intensive radiosonde observations were acquired during VPREX2010, focusing on the westward-propagating disturbances that move from the western Pacific to the South China Sea. Radiosonde observations at 06 and 18 UTC were added to the 00 and 12 UTC operational observations at Da Nang, Vietnam. Additional radiosonde observations were conducted at 00 and 12 UTC in Mactan, Philippines. In addition, exceptional successive radiosonde observations were conducted at 00 UTC in Laoag, Tanay, Legaspi, Puerto Princesa and Davao, Philippines by the great effort and support from the Philippines during VPREX2010.

An observing system experiment (OSE) was performed by comparing two analyses produced using ALEDAS2 (AFESLETKF ensemble data assimilation system 2) with and without the additional radiosonde observations from 15 September to 15 October, 2010 (hereafter referred to as CTL and VP, respectively). ALEDAS2 is an atmospheric ensemble reanalysis data assimilation system composed of the Atmospheric General Circulation Model (AGCM) for the Earth Simulator (AFES; Ofuchi et al. 2004; Enomoto et al. 2008) and the Local Ensemble Transform Kalman Filter (LETKF; Hunt et al. 2007; Miyoshi and Yamane 2007) with distance-based covariance localization. The localization length is $400 \mathrm{~km}$ in the horizontal and $0.4 \ln p$ for $\log$ pressure coordinate in the vertical. The inflation parameter is fixed to be $10 \%$ spread inflation. The data assimilation window is 6 hour. ALERA2 is an experimental ensemble reanalysis produced using ALEDAS2 and includes the analysis ensemble mean and analysis ensemble spreads for wind, temperature, humidity and geopotential height for 63 ensemble members at 48 levels with a horizontal resolution of T119 (approximately $100 \mathrm{~km}$ ). The ensemble spreads are useful for representing temporal and spatial error distributions that are consistent with actual phenomena (Moteki et al. 2007; Inoue et al. 2009; Moteki et al. 2011). Observation errors of $2 \mathrm{~m} \mathrm{~s}^{-1}$ for zonal and meridional wind speed, $0.8 \mathrm{~K}$ for temperature, $30 \%$ of the observed specific humidity, and $1.5 \mathrm{hPa}$ for pressure were used for assimilation of the radiosondes. 


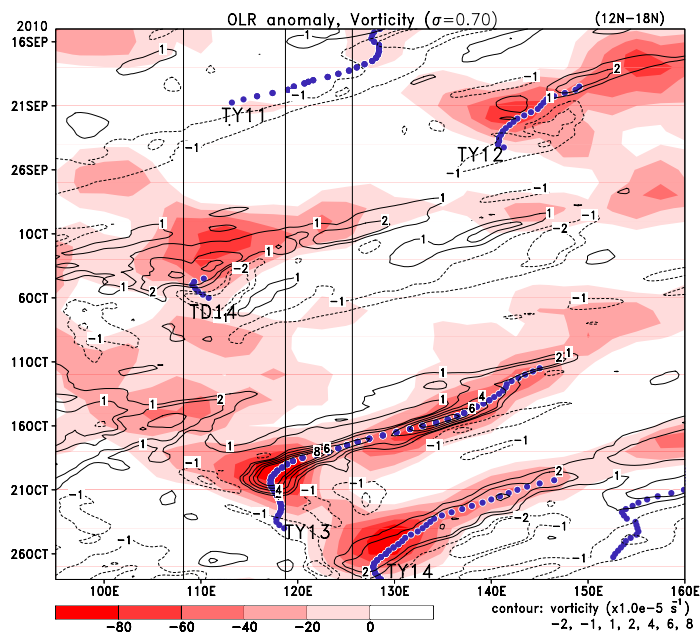

Fig. 1. Longitude-time cross section of the OLR anomaly $\left(\mathrm{W} \mathrm{m}^{-2}\right)$ averaged between $12^{\circ} \mathrm{N}$ and $18^{\circ} \mathrm{N}$ during the period from 15 September to 28 October 2010. Vorticities $\left(1 \times 10^{-5} \mathrm{~s}^{-1}\right)$ for a sigma level of 0.70 were contoured. Blue dots indicate the positions of typhoons and tropical depressions every 6 hours. Vertical lines indicate the locations of Da Nang, Puerto Princesa and Davao.

The longitude-time cross section of anomaly of the NOAA Interpolated Outgoing Longwave Radiation (OLR) (Liebmann and Smith 1996) and vorticity from ALERA2 CTL averaged between $12^{\circ} \mathrm{N}$ and $18^{\circ} \mathrm{N}$ for a sigma level of 0.7 are shown in Fig. 1. The sigma level is the pressure level normalized by the surface pressure, with sigma $=1$ at the surface and sigma $=0$ at the top of the atmosphere. A sigma level of 0.7 is used because the wind velocity is large enough to distinguish TD14 and the differences between all CTL and VP variables are large. Tropical cyclone best-tracks from the Joint Typhoon Warning Center (JTWC) are indicated by blue dots. Westward-propagating disturbances frequently occur from late September to late October, and five cases developed into four typhoons and a tropical depression (labeled as TY11, TY12, TY13, TY14 and TD14). TD14 caused heavy rainfall and severe flood damage in the coastal region of central and northern Vietnam and Hainan Island, though it did not develop into a typhoon. Figure 2 shows the black body brightness temperature (Tbb) from the Multi-functional Transport Satellite (MTSAT-1R) and hourly precipitation from the Global Satellite Mapping of Precipitation (GSMaP) data set (Okamoto et al. 2005; Kubota et al. 2007; Aonashi et al. 2009; Ushio et al. 2009) at 00 UTC on 3 October, 2010. A heavy rainfall of more than $400 \mathrm{~mm}$ over 24 hours was observed at Hue in central Vietnam (indicated by the red dot in Fig. 2).

For the analysis fields around TD14, the modification of the analysis ensemble mean variables and the reduction of the analysis ensemble spread were evaluated as the impact of the additional radiosonde observations using ALEDAS2.

\section{Modification of the ensemble mean analysis by the assimilation of additional radiosonde observations}

The TD14 related wind speed, temperature and specific humidity on 3 October are compared between CTL and VP in Figs. 3 and 4 for a sigma level of 0.7. The 3rd of October was the 19 th day after the assimilation began. The additional radiosonde modifications are significant, including the decrease in easterlies to the north of the TD $\left(>4 \mathrm{~m} \mathrm{~s}^{-1}\right)$, the increase in westerlies to the south $\left(2-4 \mathrm{~m} \mathrm{~s}^{-1}\right)$, the increase in southerlies to the east $\left(2-4 \mathrm{~m} \mathrm{~s}^{-1}\right)$, the increase in temperature to the northeast $\left(>1^{\circ} \mathrm{C}\right)$, and the increase in specific humidity to the east $\left(>3 \mathrm{~g} \mathrm{~kg}^{-1}\right)$. Southwestern winds to the south of TD14 are also significantly modified.

The wind speed and temperature modifications are larger

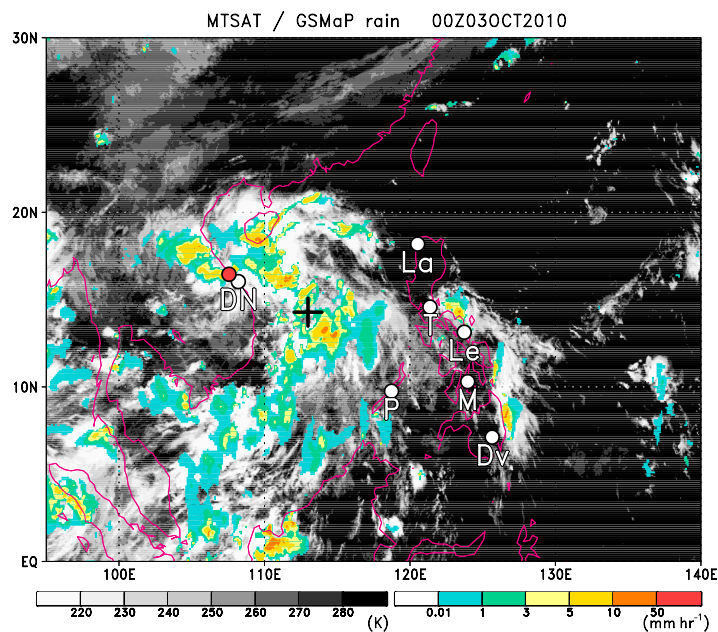

Fig. 2. Tbb from MTSAT-1R and hourly GSMaP precipitation at 00 UTC on 3 October, 2010. White dots indicate the stations of the assimilated radiosonde observations. DN, La, T, Le, M, P and Dv represent Da Nang, Laoag, Tanay, Legaspi, Mactan, Puerto Princesa and Davao, respectively. The red dot represents the Hue rain gauge station. The crosshair represents the center of the maximum vorticity for TD14.

than the observational errors used in the assimilation system of ALERA2 $\left(2 \mathrm{~m} \mathrm{~s}^{-1}\right.$ and $\left.0.8 \mathrm{~K}\right)$. Larger modification compared to observational error considers the modification to be significant. The $3 \mathrm{~m} \mathrm{~s}^{-1}$ modification of $10 \mathrm{~m} \mathrm{~s}^{-1}$ southerly winds to the east of TD14 is particularly large and notably influences the strong southerly wind characteristics of the tropical depression. The zonal wind modification is large near Hainan Island, where heavy rainfall occurred. The specific humidity observational error is variably set to $30 \%$ of the observation value. The specific humidity varies by more than $3 \mathrm{~g} \mathrm{~kg}^{-1}$ near the Philippines. The increase of specific humidity near the Philippines appears to be consistent with the precipitation pattern in Fig. 2. These variables in CTL are much closer to JRA-55 (Kobayashi et al. 2015) which assimilates the VPREX2010 data through the GTS (Global Telecommunication System) report than those in VP (not shown). Thus, the assimilation of the additional radiosondes is found to be effective for the TD14 analysis. These results suggest that radiosonde observations in Vietnam and the Philippines significantly impact on heavy rainfall and flood analyses associated with TD14.

The ensemble spread of meridional wind in CTL and VP on 3 October are shown in Fig. 5. The ensemble spreads in CTL are generally smaller than those in VP. However, the ensemble spreads in the South China Sea and south of the Indochina Peninsula in CTL are larger than those in VP. The increase of the spread in CTL would be related to the increase of wind speed because strong TD14 is represented in CTL. Based on the longitude-time cross section of meridional wind spread of CTL (not shown), the maximum ensemble spread for meridional wind propagates westward from approximately $140^{\circ} \mathrm{E}$ accompanied by the disturbance. Just after the spread reached a maximum in the South China Sea, the depression developed to TD 14.

Modifications of TY11 and TY13 were also significant (not shown). As for TY11 in CTL, increases in meridional wind ( $>$ $\left.4 \mathrm{~m} \mathrm{~s}^{-1}\right)$ and zonal wind $\left(>4 \mathrm{~m} \mathrm{~s}^{-1}\right)$, temperature $\left(>1{ }^{\circ} \mathrm{C}\right)$ and specific humidity $\left(>3 \mathrm{~g} \mathrm{~kg}^{-1}\right)$ were found compared to those in VP. As for TY13, the modifications became larger (increases in meridional winds of $4-5 \mathrm{~m} \mathrm{~s}^{-1}$, zonal winds of $4-8 \mathrm{~m} \mathrm{~s}^{-1}$, temperature of $1-1.5^{\circ} \mathrm{C}$ and specific humidity of $2-3 \mathrm{~g} \mathrm{~kg}^{-1}$ ) as it approached to the Philippines especially in the southeast quadrant.

\section{Expected analysis error reduction in ALERA2 from the analysis ensemble spread}

In order to investigate the impact of observations quantita- 

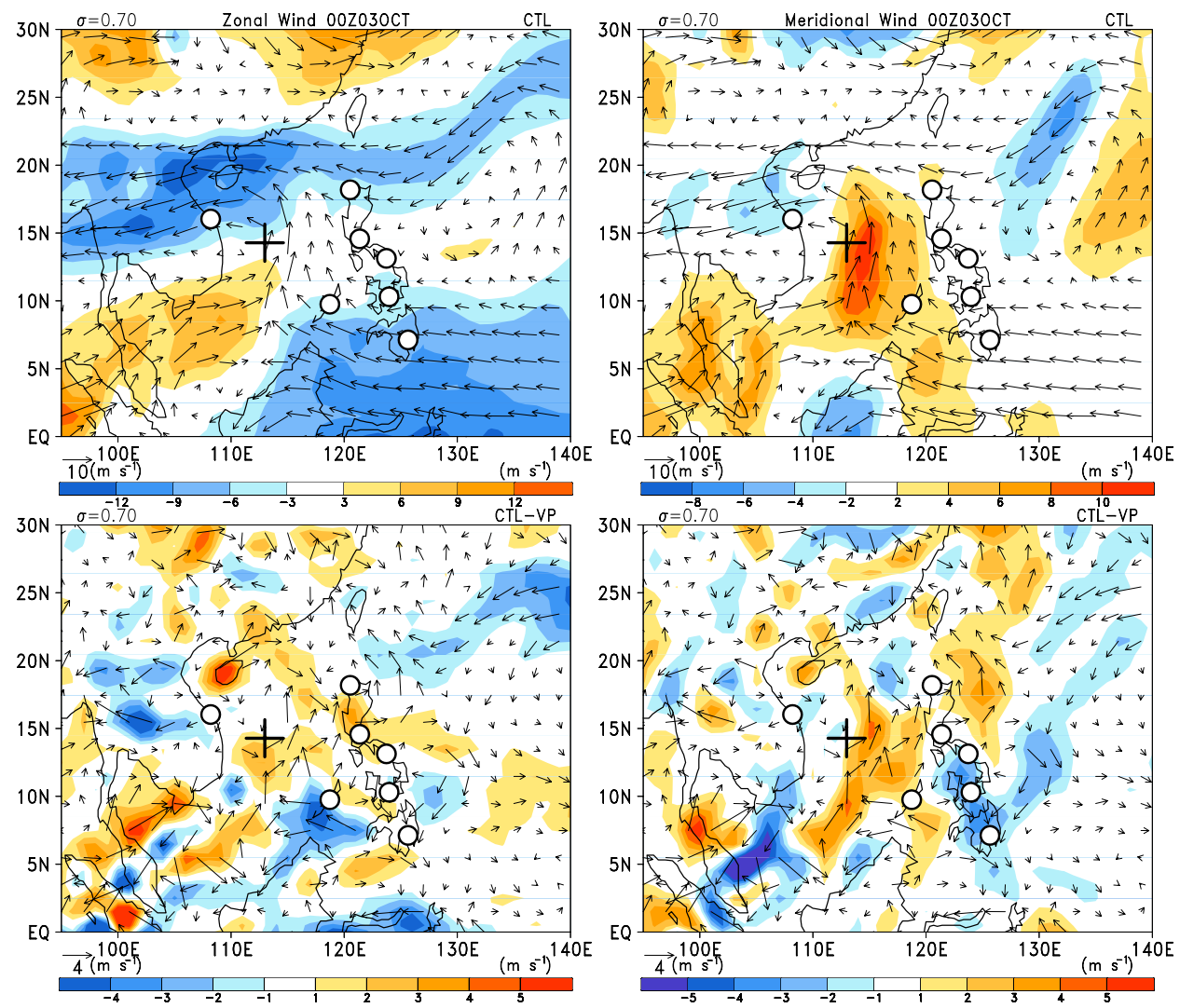

Fig. 3. Zonal (left) and meridional (right) wind speeds for a sigma level of 0.70 at $00 \mathrm{UTC}$ on 3 October, 2010. CTL and the CTL-VP difference are shown in the top and bottom panels. Vectors in the top and bottom panels indicate CTL wind vectors and CTL-VP differential wind vectors. White dots indicate the stations of the assimilated radiosonde observations. The crosshair represents the center of the maximum vorticity for TD14.
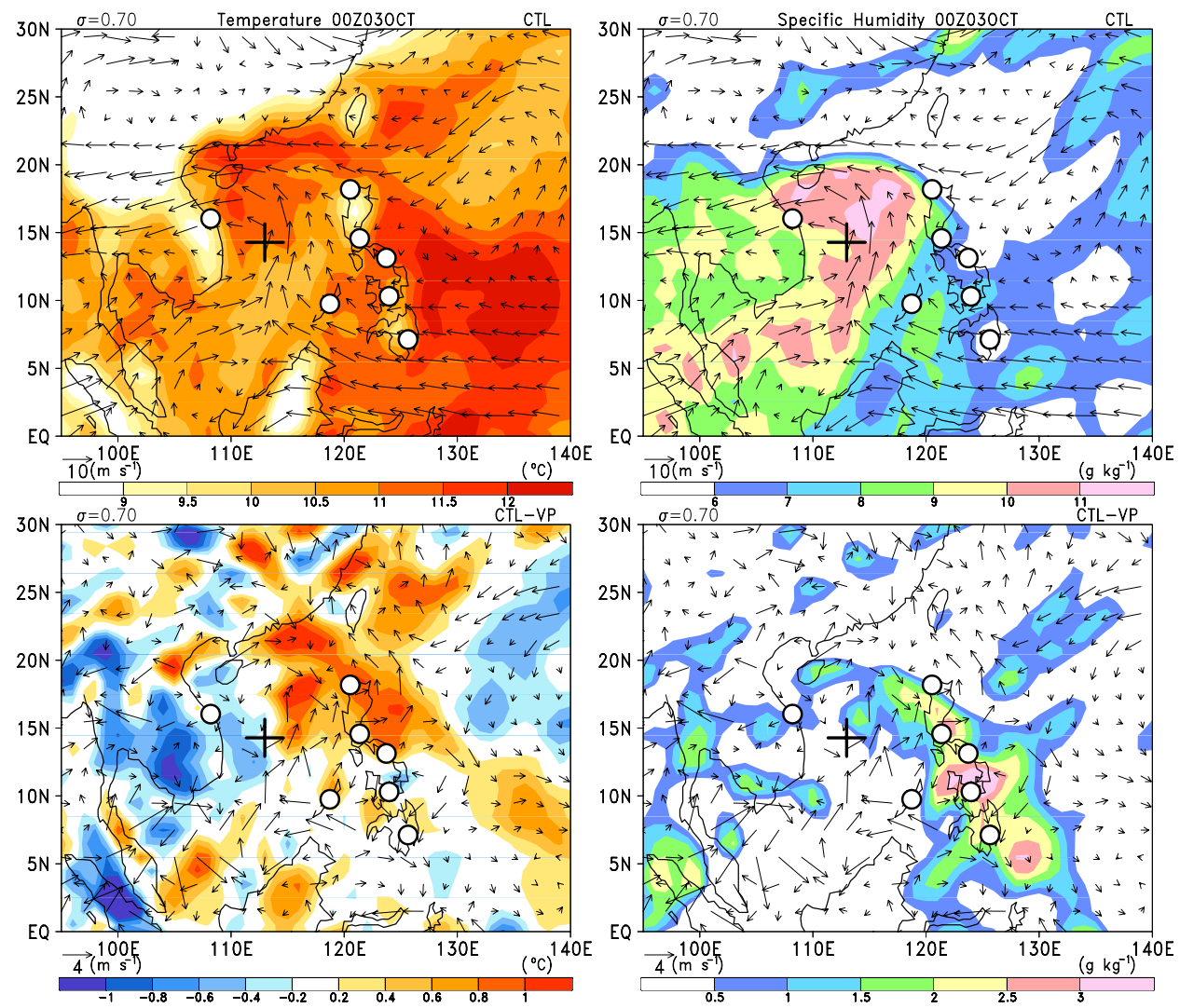

Fig. 4. As in Fig. 3, but for the temperature (left) and specific humidity (right). 

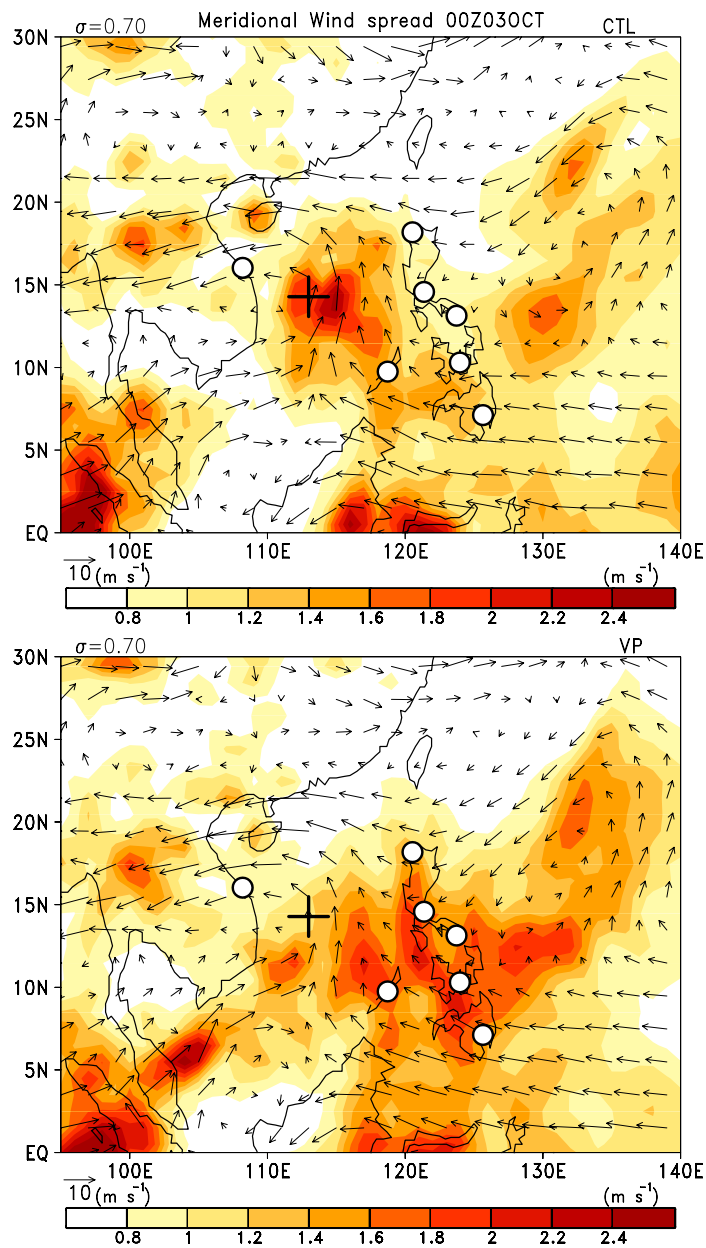

Fig. 5. Ensemble spread of meridional wind (shaded) and wind vector of CTL (top) and VP (bottom) for a sigma level of 0.7 at 00 UTC on 3 October, 2010. The crosshair represents the center of the maximum vorticity for TD14.

tively, the longitude-time cross section of the spread difference between CTL and VP (VP-CTL) is shown in Fig. 6. The ensemble spread represents the analysis accuracy in the LETKF, so that we would expect a reduced (increased) ensemble spread corresponds to a reduced (increased) analysis error. The positive differences (warm colors) in Fig. 6 correspond to the reduction of the analysis ensemble spread or reduction of the analysis error. Large positive values are displayed between $110^{\circ} \mathrm{E}-130^{\circ} \mathrm{E}$ and centered at approximately $120^{\circ} \mathrm{E}-125^{\circ} \mathrm{E}$, where the Philippines observations are located. Additional observations reduced the meridional wind spread associated with TD14 by more than $0.8 \mathrm{~m} \mathrm{~s}^{-1}$. Moreover, the positive differences of the spread to the east of Davao, which corresponding to the westward-propagating disturbance, indicate that the analysis fields to the east of Davao are modified by the additional observations to the west of Davao. It means that the prediction of the disturbance was indirectly improved.

On the other hand, it is interesting that negative values indicating increase of spread due to the additional observations are found just before the development of TD14. In the case of TD14, a negative spread difference indicates that VP fails to correctly represent analysis uncertainty. This is because strength of the developing TD14 in CTL was analyzed well due to the additional observations, whereas that in VP was not analyzed without the observations. Such difference of analyzed fields around TD14 between CTL and VP indicates that the small disturbance in the early developing stage of TD14 is not represented well in VP due to the lack of observations.

In Fig. 6, the spread reduction associated with TY11 and

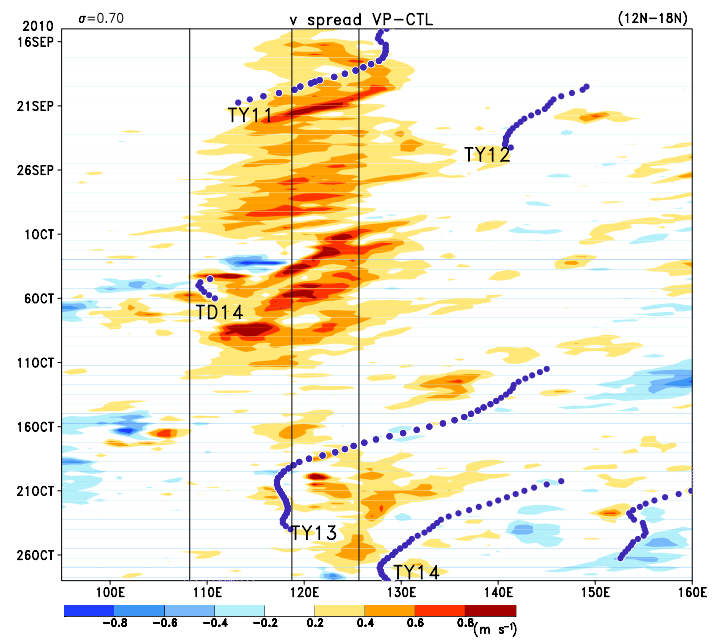

Fig. 6. Longitude-time cross section of the meridional wind spread difference (VP-CTL) for a sigma level of 0.70 averaged between $12^{\circ} \mathrm{N}$ and $18^{\circ} \mathrm{N}$ during the period of 15 September to 28 October, 2010.

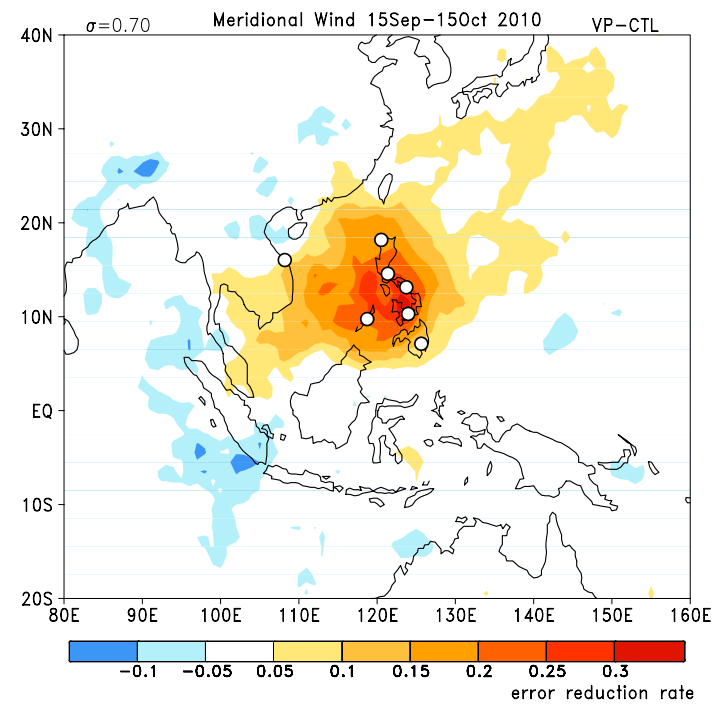

Fig. 7. Analysis error reduction rate of meridional wind for a sigma level of 0.70 averaged from 15 September to 15 October, 2010. White dots indicate the stations of the assimilated radiosonde observations.

TY13 is also confirmed. As for TY11 just after the beginning of OSE, meridional wind spread is significantly reduced in the eastern part of the typhoon $\left(>0.8 \mathrm{~m} \mathrm{~s}^{-1}\right)$. As for TY13, meridional wind spread is slightly reduced during the passage over the Philippines although the assimilation of the additional observation has been finished before the landing.

Analysis error reduction rate of the meridional wind was averaged from 15 September to 15 October, as shown in Fig. 7. The analysis error reduction rate is defined by the analysis ensemble spread difference (VP-CTL) divided by the spread of VP (Moteki et al. 2011). The analysis ensemble spread reduction rate (\%) at each grid is defined by:

$$
100 \times \frac{S_{w / o}-S_{w}}{S_{w / o}} \times \frac{K_{s}}{K}
$$

where Sw and Sw/o are the analysis ensemble spreads from the experiments with and without the assimilation of the VPREX2010 data. $\mathrm{K}$ represents the total number of grid points during the averaged period. Ks represents the number of grid points at which the significant spread differences are extracted using a statistical 
significance test.

Significant improvements of over $25 \%$ can be seen near the Philippines, while improvements of over $10 \%$ occurred near the South China Sea and the Philippines Sea. Greater than 5\% error reduction regions are distributed across the Indochina Peninsula, southern South China Sea and western pacific to the southern Japan. Error reduction rate is relatively small around Da Nang compared to over the Philippines in spite of additional radiosonde observations at 06 and 18 UTC. This may be because operational radiosonde observations in Vietnam are also successively conducted at 00 and 12 UTC in all upper air stations including Da Nang. In the Philippines, on the other hand, operational radiosonde observation had not always been conducted at all the upper air stations at that time. Therefore, it is considered that the large impact was appeared especially over the Philippines.

\section{Summary}

The present study investigated the impact of additional radiosonde observations during VPREX2010 on analysis fields of disturbances over the South China Sea using an ensemble reanalysis of ALERA2. A westward-propagating disturbance (TD14) caused heavy rainfall and flooding on the east coast of Vietnam and Hainan Island from 29 September to 4 October, 2010. It is found that the analysis of TD14 in the South China Sea was largely different between the two objective analysis datasets with and without the assimilation of additional radiosonde observations.

The westerly to the south of TD14 and southerly to the east increased by $2-4 \mathrm{~m} \mathrm{~s}^{-1}$ when the additional radiosonde observations were assimilated. In addition, the temperature increased by $>1{ }^{\circ} \mathrm{C}$ to the northeast of TD14, and the specific humidity varied by more than $3 \mathrm{~g} \mathrm{~kg}^{-1}$ to the east of TD14.

Large ensemble spreads of meridional wind were found to propagate westward following the disturbance. TD14 was generated just after the spread reached a maximum in the South China Sea. A large ensemble spread near TD14 appeared to be associated with strong winds around TD14, which were detected only with the additional observations.

During the period from 15 September to 15 October, 2010, the analysis ensemble spread decreased by $5-25 \%$ for the region extending from the southern South China Sea to the Philippines Sea and western Pacific to the south of Japan.

These results suggest that some disturbances in an early stage of development in the South China Sea are not detected well by operational observations, and that analysis of disturbances in the South China Sea would be performed more accurately with additional radiosonde observations in Vietnam and the Philippines.

In order to more accurately evaluate the analysis fields, and to estimate the impact of the additional observations on heavy rainfall and flood associated with TD14, verification such as comparison between analysis and other independent observations, comparison between the forecasts with and without the additional observations should be addressed in the future.

\section{Acknowledgments}

The Earth Simulator was used with support from JAMSTEC. The ALERA2 data set is available from http://www.jamstec.go.jp/ esc/research/oreda/products/index.html. The GSMaP products were distributed by the Earth Observation Research Center, Japan Aerospace Exploration Agency. We acknowledge Dr. Esperanza O. Cayanan, Dr. Susan R. Espinueva, Dr. Nathaniel T. Servando, Dr. Tran Quang Chu, Dr. Nguyen Van Tue, Mr. Hoang Qin Hiep and the operational staff of PAGASA and NHMS for their help conducting radiosonde observations at Mactan and Da Nang.

Edited by: K. Ito

\section{References}

Aonashi, K., J. Awaka, M. Hirose, T. Kozu, T. Kubota, G. Liu, S. Shige, S. Kida, S. Seto, N. Takahashi, and Y. N. Takayabu, 2009: GSMaP passive, microwave precipitation retrieval algorithm: Algorithm description and validation. J. Meteor. Soc. Japan, 87A, $119-136$.

Enomoto, T., A. Kuwano-Yoshida, N. Komori, and W. Ofuchi, 2008: Description of AFES 2: improvements for high-resolution and coupled simulations. High Resolution Numerical Modelling of the Atmosphere and Ocean, K. Hamilton and W. Ohfuchi, Eds., Springer, New York, 77-97.

Enomoto, T., T. Miyoshi, Q. Moteki, J. Inoue, M. Hattori, A. KuwanoYoshida, N. Komori, and S. Yamane, 2013: Observing-system research and ensemble data assimilation at JAMSTEC. Data Assimilation for Atmospheric, Oceanic and Hydrologic Applications (Vol. II), S. K. Park and L. Xu, Eds., 509-526, Springer.

Hunt, B. R., E. J. Kostelich, and I. Szunyogh, 2007: Efficient data assimilation for spatiotemporal chaos: A local ensemble transform Kalman filter. Phys. D, 230, 112-126.

Inoue, J., T. Enomoto, T. Miyoshi, and S. Yamane, 2009: Impact of observations from Arctic drifting buoys on the reanalysis of surface fields. Geophys. Res. Lett., 36, L08501.

Kobayashi, S., Y. Ota, Y. Harada, A. Ebita, M. Moriya, H. Onoda, K. Onogi, H. Kamahori, C. Kobayashi, H. Endo, K. Miyaoka, and K. Takahashi, 2015: The JRA-55 reanalysis: General specifications and basic characteristics. J. Meteor. Soc. Japan, 93, 5-48.

Kubota, T., S. Shige, H. Hashizume, K. Aonashi, N. Takahashi, S. Seto, M. Hirose, Y. N. Takayabu, K. Nakagawa, K. Iwanami, T. Ushio, M. Kachi, and K. Okamoto, 2007: Global precipitation map using satelliteborne microwave radiometers by the GSMaP project: Production and validation. IEEE Trans. Geosci. Remote Sens., 45, 2259-2275.

Liebmann, B., and C. A. Smith, 1996: Description of a complete (interpolated) outgoing longwave radiation dataset. Bull. Amer. Meteor. Soc., 77, 1275-1277.

Miyoshi, T., and S. Yamane, 2007: Local ensemble transform Kalman filtering with an AGCM at a T159/L48 resolution. Mon. Wea. Rev., 135, 3841-3861.

Miyoshi, T., S. Yamane, and T. Enomoto, 2007: The AFES-LETKF Experimental Ensemble Reanalysis: ALERA. SOLA, 3, 45-48

Moteki, Q., K. Yoneyama, R. Shirooka, H. Kubota, K. Yasunaga, J. Suzuki, A. Seiki, N. Sato, T. Enomoto, T. Miyoshi, and S. Yamane, 2011: The influence of observations propagated by convectively coupled equatorial waves. Quart. J. Roy. Meteor. Soc., 137, 641-655.

Moteki, Q., R. Shirooka, K. Yoneyama, B. Geng, M. Katsumata, T. Ushiyama, H. Yamada, K. Yasunaga, N. Sato, H. Kubota, K. K. Reddy, H. Tokinaga, A. Seiki, M. Fujita, Y. N. Takayabu, M. Yoshizaki, H. Uyeda, and T. Chuda, 2007: The impact of the assimilation of dropsonde observations during PALAU2005 in ALERA. SOLA, 3, 97-100.

Ofuchi, W., H. Nakamura, M. K. Yoshioka, T. Enomoto, K. Takaya, X. Peng, S. Yamane, T. Nishimura, Y. Kurihara, and K. Ninomiya, 2004: $10-\mathrm{km}$ mesh meso-scale resolving simulations of the global atmosphere on the Earth Simulator: Preliminary outcomes of AFES (AGCM for the Earth Simulator). J. Earth Simulator, 1, $8-34$.

Okamoto, K., T. Iguchi, N. Takahashi, K. Iwanami, and T. Ushio, 2005: The Global Satellite Mapping of Precipitation (GSMaP) project. 25th IGARSS Proceedings, 3414-3416.

Ushio, T., T. Kubota, S. Shige, K. Okamoto, K. Aonashi, T. Inoue, N. Takahashi, T. Iguchi, M. Kachi, R. Oki, T. Morimoto, and Z. Kawasaki, 2009: A Kalman filter approach to the Global Satellite Mapping of Precipitation (GSMaP) from combined passive microwave and infrared radiometric data. J. Meteor. Soc. Japan, 87A, $137-151$.

Yokoi, S., and J. Matsumoto, 2008: Collaborative effects of cold surge and tropical depression-type disturbance on heavy rainfall in central Vietnam. Mon. Wea. Rev., 136, 3275-3287.

Yokoi, S., T. Satomura, and J. Matsumoto, 2007: Climatological characteristics of the intraseasonal variation of precipitation over the Indochina Peninsula. J. Climate, 20, 5301-5315. 